\title{
Percepción de conductas comunicativas racistas: un estudio con estudiantes de ELE de un Aula de Enlace
}

\author{
CRISTINA SEGOVIA BARBERÁN \\ Universidad Camilo José Cela \\ cristina.segovia.barberan@gmail.com
}

\section{Resumen}

Los menores de edad que llegan a España sin tener nociones de la lengua son más de los que acostumbramos a considerar y conforman un paradigma especial en el mundo de ELE. Al estar en edad educativa obligatoria, los gobiernos autonómicos han propuesto algunas iniciativas para la incorporación e inclusión de estos alumnos, como es el caso de las Aulas de Enlace en Madrid. La odisea para muchos de estos menores empieza en este punto en el que tienen que aprender el idioma a un ritmo acelerado para incorporarse a un sistema educativo nuevo y luchar por su futuro. Con todo lo anterior, aparece una dificultad aún mayor: la discriminación racista. Y es que las conductas comunicativas racistas forman parte de nuestra conciencia colectiva y se materializan mediante el discurso y la comunicación no verbal (Van Dijk, 2010). Se ha diseñado una investigación para conocer si existen diferencias en la percepción de los comportamientos comunicativos racistas entre un grupo de aprendientes de español de un Aula de Enlace y un grupo de estudiantes españoles del mismo centro y la misma edad, atendiendo a los eufemismos descorteses, rasgos pragmáticos y comunicación no verbal. Para ello, se han creado dos cuestionarios paralelos que plantean distintos tipos de situaciones y cuestiones para conocer la opinión de los alumnos. Así, debe tenerse en cuenta que los datos obtenidos no son fruto de un corpus real y estudiado de la lengua sino de la percepción de los informantes, subrayando la capacidad revalorizadora de una lengua sobre su uso no discriminador en el ámbito de la diferencia étnica y cultural.

\section{Palabras clave}

Racismo; sociopragmática; discriminación; eufemismos; aula de enlace; ELE; infortunios; comunicación no verbal. 


\title{
Perception of racist communicative behaviours: a study with ELE students in a Spanish as a Foreign Language Class
}

\begin{abstract}
There are more minors arriving in Spain without any knowledge of the language than we are used to considering, and they form a special paradigm in the world of ELE. As they are of compulsory school age, the regional governments have proposed some initiatives for the incorporation and inclusion of these students, as is the case of the Aulas de Enlace in Madrid. The odyssey for many of these children begins at this point when they have to learn the language at an accelerated pace in order to join a new educational system and fight for their future. With all of the above, an even greater difficulty arises: racist discrimination. Racist communicative behaviours are part of our collective consciousness and are materialised through discourse and non-verbal communication (Van Dijk, 2010). A research study was designed to find out whether there are differences in the perception of racist communicative behaviours between a group of Spanish learners in an Aula de Enlace and a group of Spanish students from the same school and of the same age, in view of impolite euphemisms, pragmatic traits and non-verbal communication. For this purpose, two parallel questionnaires have been created which pose different types of situations and questions to ascertain the students' opinions. Thus, it should be borne in mind that the data obtained are not the result of a real and studied corpus of the language but of the perception of the informants, underlining the revalorising capacity of a language on its non-discriminatory use in the field of ethnic and cultural difference.
\end{abstract}

\section{Keywords}

Racism; sociopragmatics; discrimination; euphemisms; spanish as a foreign language; misfortunes; non-verbal communication.

Recibido el 30/06/2021

Aceptado el 10/11/2021 


\section{Introducción}

Las aulas de idiomas constituyen un punto de encuentro para personas de distintas culturas y procedencias. El Marco Común Europeo de Referencia para las Lenguas (Consejo de Europa, 2001) y la experiencia e investigación de numerosos profesionales sitúan al enfoque intercultural como un indiscutible compañero de viaje en la aventurada tarea de enseñar una lengua extranjera. Por parte del aprendiente, como asegura Byram (2001), se espera que se produzca un acercamiento entre culturas, creando vínculos más respetuosos y empáticos entre personas que el azar hizo nacer en puntos remotos. Pero bien sabemos que no siempre es así. Las entidades educativas cargan con las tensiones y paradojas sociales de un sistema democrático que a su vez aguanta el peso de intereses ajenos (Chomsky, 2001).

En el caso de las Aulas de Enlace, cuyo fin es la integración educativa de niños y adolescentes que desconocen la lengua, las diferencias culturales pueden ser foco de ataques racistas y discriminatorios. Como apunta García (2004), llegar a un país nuevo suele ser asociado por este tipo de alumnado con ideas como puerta, apoyo, puente y esperanza. Sin embargo, muchas veces no son más que un grupo de náufragos que siguen aislados al llegar a tierra (Miláns, 2007).

En este artículo se pretende investigar sobre las conductas comunicativas racistas que perciben los estudiantes de ELE mediante eufemismos descorteses, rasgos pragmáticos y comunicación no verbal. Para ello, se ha contado con un grupo de diez alumnos adolescentes de distintas nacionalidades, estudiantes del Aula de Enlace en un centro educativo de la Comunidad de Madrid. Es una investigación que pone de manifiesto aquello que los aprendientes de español pueden enseñarnos en un uso cortés no discriminador de la lengua al referirnos a las diferencias étnicas.

La libertad, así como la igualdad y la justicia, han de construirse mediante la práctica, el diálogo y la realidad, aunque esta pueda ser opresora de por sí (Freire, 2003). De tal manera, el discurso se convierte en el primer agente para reproducir - 0 dejar de hacerlo - una ideología racista y discriminatoria infundida por un «sistema social de dominación étnico-racial» (Van Dijk, 2010, p. 94) que hace palpable la desigualdad social en la mayoría de contextos.

¿Cómo perciben una agresión a su imagen los aprendientes de distintas etnias? ¿Están equivocados, o suelen acertar en su interpretación de las intenciones de los hablantes nativos cuando se refieren a ellos? El principal objetivo es conocer de qué manera los estudiantes de ELE, en el contexto educativo de un Aula de Enlace, perciben los discursos racistas y las conductas comunicativas discriminatorias.

\section{Racismo y lenguaje: una mirada a las Aulas de Enlace}

\subsection{Discurso racista}

La discriminación de distintos grupos etnoraciales desencadena una serie de estereotipos, creencias y actitudes que quedan impregnados en el lenguaje. Este, a su 
vez, continúa propagando la discriminación y es así como el racismo y el discurso entran en un círculo que parece no tener fin (Molina-Niñirola, 2005).

Para entender el calado que tienen las ideas de racismo y de inmigración en nuestro lenguaje es preciso partir de una perspectiva histórica. Como explica Van Dijk (2003a), España siempre ha sido la frontera entre Europa y el resto de países del Sur, a menudo relacionados en el imaginario colectivo con la delincuencia, la inseguridad y las invasiones. No obstante, España también ha sido, durante muchos años, un país de emigración. Dicho en otras palabras, podríamos ver a nuestros antepasados en los ojos de las personas que ahora arriban a nuestros puertos.

Todos estos encuentros étnicos han marcado nuestra conciencia colectiva mediante actitudes racistas y una mirada vertical hacia los países del Sur y sus gentes, colocándoles siempre en una posición de inferioridad. Estos sedimentos en la conciencia colectiva de un país o cultura se hacen palpables a través de los medios de comunicación, de los discursos políticos y del lenguaje cotidiano de su comunidad, además de perpetuarse en los sistemas educativos y laborales (Van Dijk, 2010).

A lo anterior hay que sumarle que, como exponen Calero, Forgas y Lledó (2002), el discurso humano suele envolver el menosprecio de lo ajeno. Algo que, inevitable e inconscientemente, nace del temor a lo desconocido. Las autoras lanzan ejemplos fraseológicos cargados de connotaciones peyorativas que todos hemos escuchado, como «trabajar como un negro», «ir hecho un gitano» o «hacer el indio». De esta manera, mediante el discurso, simplificamos la realidad cayendo en estereotipos y tópicos que nos permiten alejarnos de ese temor a lo ajeno y reducir las complejidades socioculturales que toda comunidad de habla entraña.

Si está usted leyendo estas páginas, probablemente no haga falta reivindicar el poder de las palabras. Islas (2005) argumenta que no es lo mismo decir «feto»o «bebé no nacido», «vicio» o «enfermedad» o, llevado al caso que nos compete, «niño/a inmigrante» o «MENA». Muchas de las palabras que utilizamos van más allá de ser simples unidades léxicas, pues están cargadas de connotaciones o ponen el énfasis en determinados aspectos que delatan nuestra manera de pensar. De tal modo, «no solo la manera como percibimos el mundo influye en nuestro lenguaje, sino que el lenguaje que usamos afecta de manera profunda la forma como pensamos» (p. 17).

Matias \& DiAngelo (2013) hablan de las respuestas incómodas de la gente blanca en conversaciones exponencialmente discriminatorias. "Yo no soy racista, pero...», pausas, repeticiones, titubeos y autocorrecciones. Explican la previsibilidad de estas reacciones como una especie de «neurosis emo-cognitiva» derivada del empeño de hablar de la raza en un mundo que insiste en que la raza no importa. Cerreras i Goicoechea y Pérez (2010 citados en Mármol, 2019) comprenden el tema candente de la mediación lingüística y cultural como resultado natural de la convivencia de diferentes culturas, una nueva imagen social que, en ocasiones, conduce a conflictos comunicativos.

Dicha mediación es un proceso prometedor que da la mano entre distintos interlocutores para mejorar su comunicación lingüística y cultural (Trovato, 2014). 
El desafío que entraña todo esto no es solo la existencia y la identificación de los discursos y las prácticas racistas en la cotidianidad, sino la reflexión crítica del uso de la lengua junto a la revalorización de la misma. En palabras de Ortuño (2016), deconstruir los discursos racistas es como quitar un microchip que nos viene de fábrica y nos hace repetir determinados comportamientos y razonamientos, muchas veces sin ser plenamente conscientes.

\subsubsection{Eufemismos descorteses}

El eufemismo es «el fenómeno lingüístico mediante el cual se esquivan algunas palabras o se sustituyen por otras. Dicho con otro giro: el término eufemismo engloba una serie de manifestaciones lingüísticas cuya causa psicológica es la interdicción» (Sempere, 1971, p. 176).

En el caso de las razas y el color de piel, algo tan irrenunciable, tan identitario y tan ingrávido a la vez, los eufemismos aparecen como preservación del bien sentir de la raza blanca, sin inmutar su posición privilegiada. Estamos hablando de ejemplos tan imprecisos y ambiguos como «persona de color» (González, 2003). Puede que sea fruto de la herencia sociolingüística, de nuestro bagaje cultural o de nuestra propia carencia crítica con el lenguaje, pero es innegable que adoptamos un discurso de «minimizar los actos descorteses» (Leech, 1983) cuando hablamos de ciertas razas o culturas.

Casas (1993 citado en Crespo Fernández, 2005) identifica dos partes clave en este fenómeno discursivo: la sustitución eufemística y su conversión al disfemismo. De tal manera, el eufemismo que nace de unas condiciones sociopragmáticas concretas para suavizar un concepto ofensivo acaba adquiriendo las mismas connotaciones negativas que el término al que sustituye, contaminando, así, su condición eufemística. Es por esta razón por la que puede sostenerse que el eufemismo es un «fenómeno social, inestable y relativo» (p. 70). Como explica Casas en Pizarro (ed.) (2018), no existen palabras de por sí eufemísticas o disfemísticas, sino palabras que actúan como eufemismos o disfemismos dentro de un contexto comunicativo concreto con una intención específica.

Ya que hemos nombrado la descortesía y el disfemismo, cabe señalar su clara relación en cuanto a la construcción de una imagen social negativa. Si tenemos en cuenta la rápida capacidad de transformación del eufemismo al disfemismo, no nos equivocaríamos al alertar que, los eufemismos, al mismo tiempo que buscan alejarse de dicha imagen social negativa, se acercan peligrosamente a ella (Díaz Pérez, 2012).

Sin duda, el eufemismo está en una cuerda floja y aun así nos jugamos el pescuezo a diario. Es por ello interesante recordar sus funciones sociales, entre las que podemos encontrar: ser respetuoso, otorgar dignificación y sensibilización social, tratar temas tabús como la religión, el sexo o la muerte y evitar agravios étnicos, entre otros (Domínguez, 2004). Llegados a este punto, deberíamos preguntarnos por qué decir «negro» nos parece más violento que emplear diminutivos como «negrito»o «morenito».

¿Cómo afectan dichos eufemismos a la población de raza no-blanca? Algunos estudios, como el que presentó Rafky (1970) hace ya algunas décadas, demuestran que 
estas personas, en su generalidad, prefieren que se las designe «negras» en lugar de cualquier otra palabra que trate de ocultar que su color de piel es negro, pero sin dejar de remarcarlo. Lo que ocurre en estos casos es que identificamos a las personas de otras razas como si el hecho de serlo fuera aquello que las define como seres humanos. Es más, al hablar de ellas, a pesar de estar exponiendo sus características personales o profesionales, en rara ocasión no se llega a puntualizar su procedencia o tono de piel (Freire, 2003).

Como era de esperar, palabras como «negro» han ido adquiriendo tintes de disfemismo en algunos contextos y esferas sociales. Esto es algo bueno que está trayendo el interculturalismo, la interacción horizontal de personas de distintas culturas y etnias. Autores como Dassetto (2004) advierten de que estos fenómenos de multiculturalismo e interculturalismo deben ir acompañados de una inclusión real en todos los ámbitos. De lo contrario, pronto tendremos nuevos términos que añadir a la lista de eufemismos.

Con todo lo expuesto y a pesar de sus valiosas y evidentes funciones sociales, el eufemismo no deja de ser una doblez lingüística que se mueve en la paradoja de avergonzarse de la palabra sin actuar sobre la idea, manteniendo a la sociedad y su lenguaje en lo «políticamente correcto» sin concederle importancia ni espacio de reflexión al trasfondo (Casas, 1993).

\subsubsection{Identificadores de conductas comunicativas racistas}

No solo lo que decimos, como se ha expuesto hasta el momento, está cargado de significados, sentidos y connotaciones. La comunicación no verbal brinda una información valiosísima en todo proceso comunicativo. Una interpretación adecuada de los rasgos no verbales puede darnos pistas significativas sobre la intención del interlocutor (Díaz Pérez, 2012).

El discurso no está únicamente formado por los «rasgos hablantes», tal y como especifica Poyatos (2003), sino por «la triple actividad verbal-paralingüística-kinésica» (p. 74). En los discursos abiertamente racistas no cuesta encontrar gestos despectivos y posturas corporales que marcan claramente el «yo» y el «ellos». En situaciones más cotidianas, podemos distinguir (Van Dijk, 2001):

- Proxémica. Social y públicamente se suele dejar una distancia física mayor con las personas de diferente etnia. Lentin (2016) analiza el aumento de los comportamientos y ataques racistas en el transporte público en esta última década, reiterando la primacía de las voces blancas «razonables» sobre las supuestamente tendenciosas de los racistas.

- Cinésica. Los micro gestos parecen ir cargados de insolencia y desconfianza, el contacto visual disminuye y la expresión corporal tiende a ser cerrada, con posturas defensivas como los brazos cruzados.

En cuanto a los ataques racistas se tienen en cuenta los signos paralingüísticos, como reírse o escupir, los quinestésicos, como señalar con el dedo o hacer gestos 
burlescos, y otras acciones como hacer el vacío o quitar complementos u objetos personales (Placencia, 2008). Tendemos a pensar que este tipo de comportamientos son aislados, pero lo cierto es que también conforman nuestra cultura, pues son aprendidos por los individuos en su desarrollo dentro de la sociedad. Un buen criterio a tener en cuenta a la hora de valorar nuestra cultura es entender cómo valora a las otras y cómo hacemos a las otras entender la nuestra (García, 2004).

Tratando, en especial, los rasgos pragmáticos y aspectos racistas de la comunicación no verbal es ineludible volver a una de las claves del lenguaje: la interpretación. En los intercambios comunicativos, la intención no acostumbra a ser tan directa, explícita y fácil de identificar. Pueden darse, entonces, discrepancias sobre lo que varios interlocutores perciben como discriminador, racista o amenazador. Lo que normalmente ocurre es que se conforman dos grupos de opinión: los no discriminados, que se mantienen en el borde de la inocencia de las intenciones racistas, y los discriminados, que las perciben con mayor facilidad pues ejercen directamente el peso sobre sus hombros (Bañón, 2002).

Como asegura Magro (2016), todas estas situaciones pueden darse en los contextos de enseñanza de español como segunda lengua, por lo que es urgente que los profesores estemos al tanto de ellas. Dependerá del tipo de alumnado y de su situación, pero, como se presenta en el siguiente punto, hay lugares en los que es más fácil encontrase con estas tesituras tan delicadas.

\subsection{Discriminación en las Aulas de Enlace}

Atendiendo a las Instrucciones del 16 de julio de 2003 de la Viceconsejería de Educación, la Comunidad de Madrid pone en marcha el proyecto Escuelas de Bienvenida, que pretende la inclusión en el sistema educativo de los niños y adolescentes que llegan de otros países. Dentro de este contexto nacen las Aulas de Enlace para enseñar la lengua española en un periodo máximo de nueve meses y con no más de doce alumnos. Tras este tiempo se espera que los alumnos de diversas procedencias y lenguas maternas (árabe, francés, chino, inglés, ruso, alemán...) hayan alcanzado el nivel requerido para incorporarse, de lleno, a un aula ordinaria sin ningún tipo de adaptación curricular.

Con lo descrito, cabe señalar que, pese a ser un proyecto necesario, es, debido a su normativa y planificación, un tanto ilusorio. Miláns (2007) subraya dos grandes problemas: es un programa de atención a la diversidad que no busca el éxito académico sino «salir del paso», y la falta de involucración de todo el centro educativo y su comunidad para la inclusión real y el aprendizaje efectivo de los alumnos inmigrantes. Como resultado, estos niños y adolescentes comienzan a arrastrar una estela de fracaso académico y desmotivación que les mantiene aislados.

$\mathrm{Ni}$ las contadísimas investigaciones hasta el momento, ni los docentes de las aulas ordinarias, ni los profesores de ELE han llegado a un acuerdo sobre si es mejor que el alumno extranjero reciba el apoyo lingüístico dentro o fuera de su aula de referencia. De lo que no hay duda es de que, sin un clima acogedor que trabaje la diversidad y 
abrace a estos estudiantes como una parte más del grupo, ninguna opción será positiva (Goenechea, García-Fernández y Jiménez, 2011).

Asimismo, como recogen estos autores, muchos de los alumnos de las Aulas de Enlace no continúan sus estudios en esos centros, ya que suelen ser concertados o privados y no pueden permitirse la cuota. Esto conduce a una mayor hondura en el aislamiento y la discriminación de niños y adolescentes que no llevan apenas uno o dos años en el país y, pese a los esfuerzos, no dominan el idioma.

Siguiendo con lo comentado, la responsabilidad recae en las comunidades educativas que, según Lepe-Carrión (2018), operan con un «diferencialismo cultural que tiene poderosos efectos de etnización en la sociedad» (p. 13). Es por esta razón que debemos esforzarnos en hacer de la cultura un universo compartido que favorezca que los alumnos recién llegados sigan asociando sus nuevos comienzos con palabras como puerta o esperanza (García, 2004).

\section{Planteamiento del problema}

Como ya se ha planteado en la introducción y en el estado de la cuestión, esta investigación nace de un contexto real de enseñanza de español como lengua extranjera. Mediante el análisis de los datos recogidos se pretende dar respuesta a nuestro problema: ¿Existen diferencias en la percepción de los comportamientos comunicativos racistas entre un grupo de estudiantes inmigrantes de un Aula de Enlace y un grupo de estudiantes españoles del mismo centro y la misma edad?

\section{Metodología}

Para llevar a cabo esta investigación se diseñaron dos cuestionarios ${ }^{1}$ equiparables para los estudiantes de español del Aula de Enlace y los estudiantes de un aula ordinaria. A pesar de que a los alumnos únicamente se les presentaron las preguntas, el diseño de los cuestionarios se estructura en dimensiones e indicadores que permiten organizar y enfocar de una manera más precisa los datos que se pretenden recoger. Los cuestionarios se realizaron de manera presencial para asegurar la comprensión de los mismos y presentar algunos vídeos que acompañan a ciertas preguntas con el fin de asegurar su comprensión. Se hicieron el mismo día con los dos grupos por separado y una duración media de quince minutos. En primer lugar, se recalcó el tema y el objetivo de la investigación, así como el completo anonimato de sus participantes. Después, se repartieron los cuestionarios y, sin empezar a contestarlos, se leyeron conjuntamente para aclarar dudas. Las cuatro preguntas que iban enlazadas a un vídeo estaban marcadas con un asterisco para que las respondieran en último lugar, cuando todos pudieran atender a las piezas audiovisuales. Para acabar, se recogieron los cuestionarios y se abrió un turno de preguntas y reflexiones que les surgieron a los alumnos a raíz del tema tratado.

1 Véase Anexo 1 
La selección de la muestra de esta investigación ha sido un muestreo por conveniencia, dado que se han seleccionado dos grupos-clase de alumnos diferenciados que se quieren comparar. El primer grupo, Aula de Enlace, está compuesto por diez sujetos mientras que el segundo grupo, aula ordinaria, está compuesto por veintidós. Esto hace que la muestra esté compuesta por un total de 32 sujetos participantes en el estudio. Ya que la muestra ha sido seleccionada por conveniencia y su tamaño es pequeño, los resultados de este estudio no serán generalizables, sino que servirán para realizar una aproximación al campo de estudio. Esto implica que los resultados no deberían tomarse como algo representativo, sino como un hecho específico de la realidad vivida en un contexto concreto que deja la puerta abierta a futuras investigaciones.

Para analizar los datos, primero, se otorgaron valores numéricos a las respuestas y se recogieron en un Excel. Después fueron introducidas y estudiadas mediante el programa estadístico SPSS. En el siguiente epígrafe se incluyen algunas de las tablas de datos y gráficos para analizar los resultados.

\section{Análisis de resultados}

Para conducir el análisis, los resultados se han organizado en cuatro grandes grupos conforme a las dimensiones de los cuestionarios:

\subsection{Grupo de análisis 1. Discriminación en el país de origen}

En este grupo de análisis trabajamos solo con la muestra del Aula de Enlace. Solo un $30 \%$ de los alumnos extranjeros afirma que en sus países de nacimiento hay discriminación hacia las personas de otros orígenes. El 80\% de los alumnos no se sentía discriminado en su país y, del porcentaje restante, la discriminación venía determinada por su manera de ser o por sus gustos y aficiones.

Tabla 1. Discriminación racial en el país de origen

\begin{tabular}{|c|c|c|c|c|c|}
\hline & & Frecuencia & Porcentaje & $\begin{array}{l}\text { Porcentaje } \\
\text { válido }\end{array}$ & $\begin{array}{l}\text { Porcentaje } \\
\text { acumulado }\end{array}$ \\
\hline \multirow[t]{3}{*}{ Válido } & 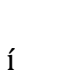 & $S$ & 30,0 & 30,0 & 30,0 \\
\hline & o & N & 70,0 & 70,0 & 100,0 \\
\hline & Total & 10 & 100,0 & 100,0 & \\
\hline
\end{tabular}


Tabla cruzada ¿Te sentías discriminado/a allí?* Género

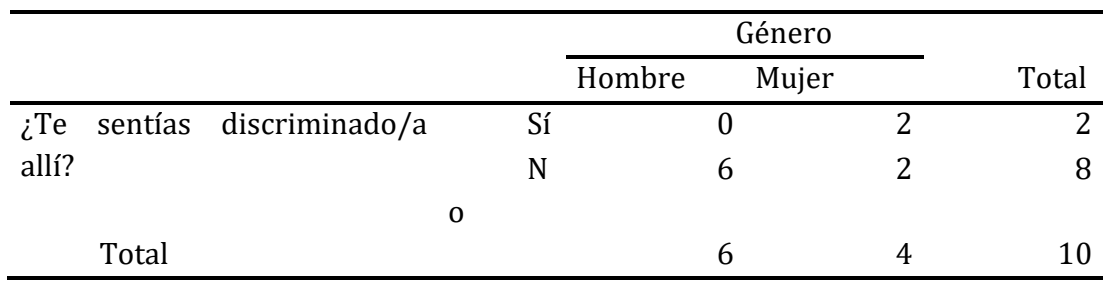

\subsection{Grupo de análisis 2. Discriminación en España}

En este caso se juntan tres análisis: el análisis global de todos los casos, los casos del Aula Enlace y los casos del aula ordinaria. Es importante comparar los tres porque los resultados son muy diferentes.

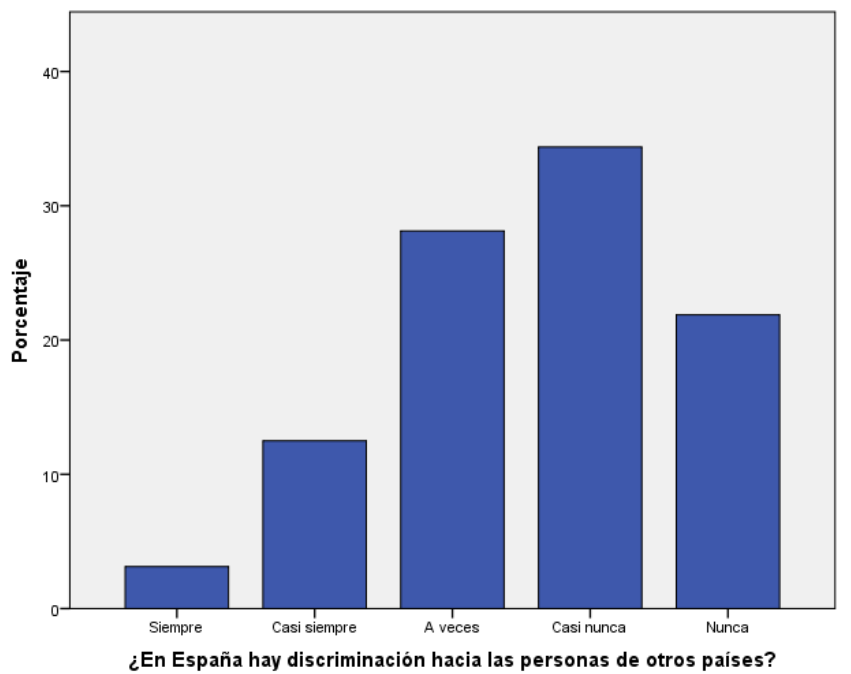

Figura 1. Percepción general sobre racismo en España

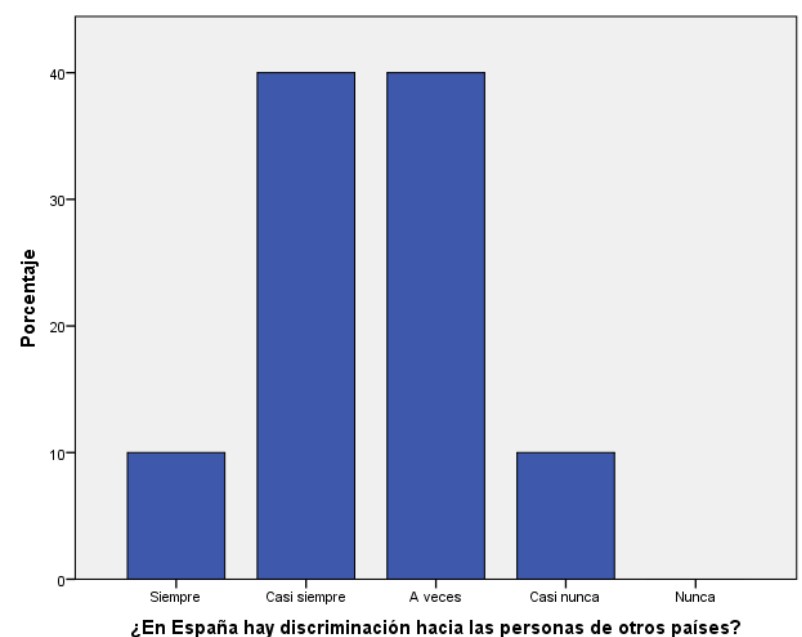

Figura 2. Percepción Aula Enlace sobre racismo en España

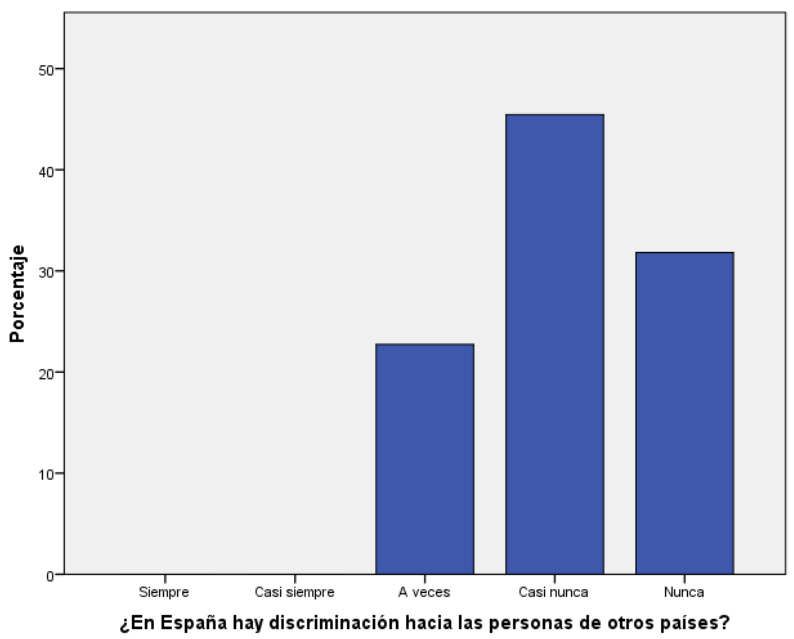

Figura 3. Percepción aula ordinaria sobre racismo en España 
El sentimiento de discriminación en el colegio también es ilustrativo. Siguiendo el mismo orden podemos observar que, mientras un $80 \%$ de los alumnos del Aula de Enlace se siente discriminado, solo un 9,1\% de los alumnos españoles lo hace.

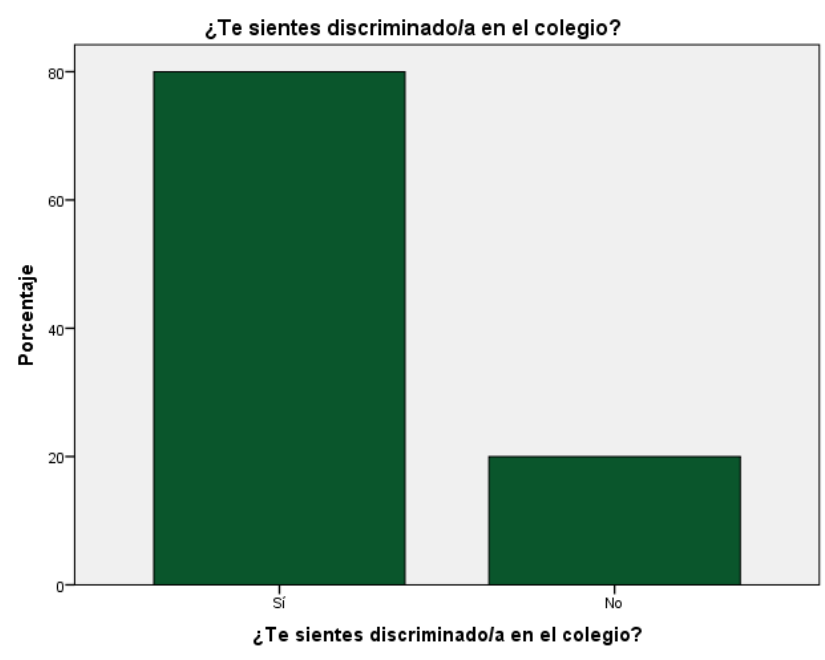

Figura 4. Sentimiento de discriminación Aula de Enlace

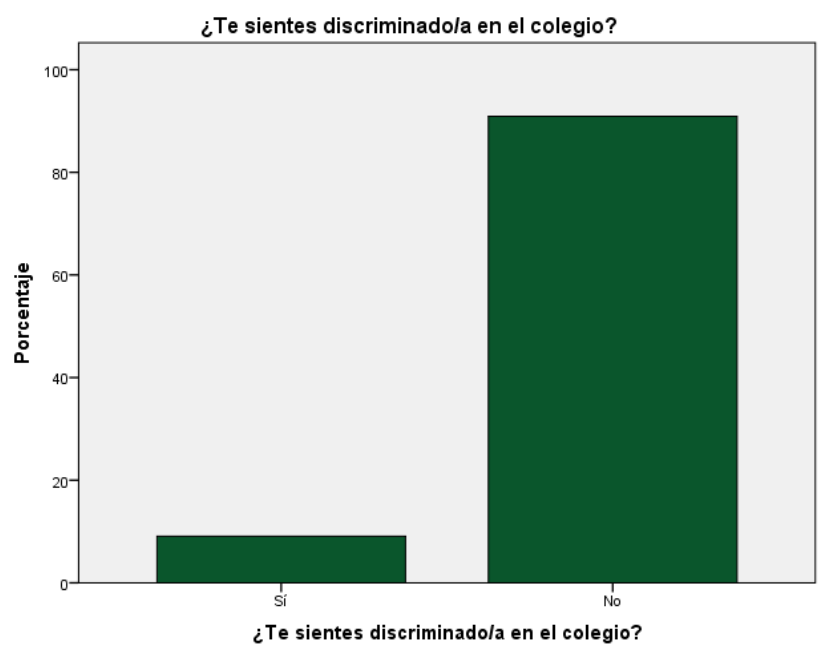

Figura 5. Sentimiento de discriminación aula ordinaria

En cuanto a las razones por las que se sienten discriminados, el 70\% de los alumnos del Aula de Enlace afirma que se debe a ser de otro país y un $10 \%$ lo atribuye a sus gustos y aficiones. En la siguiente tabla, los datos perdidos por el sistema se corresponden al $20 \%$ de los alumnos que no se sentía discriminado.

Tabla 3. Razones discriminación Aula de Enlace

Si te sientes discriminado/a, ¿por qué te sientes discriminado/a?

\begin{tabular}{clrrrr}
\hline & & & \multicolumn{2}{c}{ Porcentaje } \\
& & Frecuencia & Porcentaje & Porcentaje válido & acumulado \\
\hline \multirow{2}{*}{ Válido } & Por mis gustos y aficiones & 1 & 10,0 & 12,5 & 12,5 \\
& Por ser de otro país & 7 & 70,0 & 87,5 & 100,0 \\
& Total & 8 & 80,0 & 100,0 & \\
Perdidos & Sistema & 2 & 20,0 & & \\
Total & & 10 & 100,0 & & \\
\hline
\end{tabular}

El 9,1\% de los alumnos españoles que se siente discriminado es por su manera de ser y otras razones como la estatura.

\subsection{Grupo de análisis 3. Lingüística}

\subsubsection{Conductas comunicativas racistas}

En la primera cuestión dentro de este grupo de análisis se les pregunta a todos los alumnos si tienen compañeros racistas. Los resultados manifiestan que cinco de los 
alumnos extranjeros (50\% del total de su grupo) y cinco de los alumnos españoles $(22,7 \%$ del total de su grupo) aseguran tener compañeros racistas.

Tabla 4. Tener compañeros/as racistas

\begin{tabular}{lrrrrr}
\multicolumn{6}{c}{ ¿Tienes compañeros/as racistas? } \\
\multicolumn{7}{c}{ Frecuencia } & Porcentaje & Porcentaje válido & Porcentaje acumulado \\
\hline Válido & Sí & 10 & 31,3 & 31,3 & 31,3 \\
& No & 22 & 68,8 & 68,8 & 100,0 \\
& & & & & \\
& Total & 32 & 100,0 & 100,0 & \\
\end{tabular}

En cuanto a la pregunta de en qué consiste un ataque racista, las opciones marcadas por los alumnos también son significativas:

Tabla 5. Insultos

¿Consideras los insultos como un ataque racista?

\begin{tabular}{|c|c|c|c|c|c|}
\hline & & Frecuencia & Porcentaje & Porcentaje válido & Porcentaje acumulado \\
\hline \multirow[t]{3}{*}{ Válido } & No & 1 & 3,1 & 3,1 & 3,1 \\
\hline & Sí & 31 & 96,9 & 96,9 & 100,0 \\
\hline & Total & 32 & 100,0 & 100,0 & \\
\hline
\end{tabular}

Tabla 6. Gestos

¿Consideras los gestos como un ataque racista?

\begin{tabular}{|c|c|c|c|c|c|}
\hline & & Frecuencia & Porcentaje & Porcentaje válido & Porcentaje acumulado \\
\hline \multirow[t]{3}{*}{ Válido } & No & 19 & 59,4 & 59,4 & 59,4 \\
\hline & Sí & 13 & 40,6 & 40,6 & 100,0 \\
\hline & Total & 32 & 100,0 & 100,0 & \\
\hline
\end{tabular}

En este análisis podemos observar el claro peso que se le otorga a la comunicación verbal. Los porcentajes de todos los ataques comunicativos no verbales son iguales o inferiores a la mitad de la muestra total: solo un 50\% de los alumnos ha marcado marginación frente a un 71,9\% que ha marcado amenazas y, mientras un 96,9\% de la muestra total considera que los insultos son un ataque racista, solo un 40,6\% percibe los gestos como tal. En cuanto al 6,3\% que destacó otras opciones, todas ellas fueron relacionadas con la violencia física.

\subsubsection{Disfemismos, eufemismos, fraseología y humor}

Para empezar con este grupo de análisis, nos preguntamos por los disfemismos y eufemismos racistas, haciendo la misma pregunta adaptada a ambos grupos: 
¿Te han llamado alguna vez "negro/a", "chinito/a", “moro/a", "morenito/a", "persona de color", "sudaca", "terrorista" o "inmigrante"?

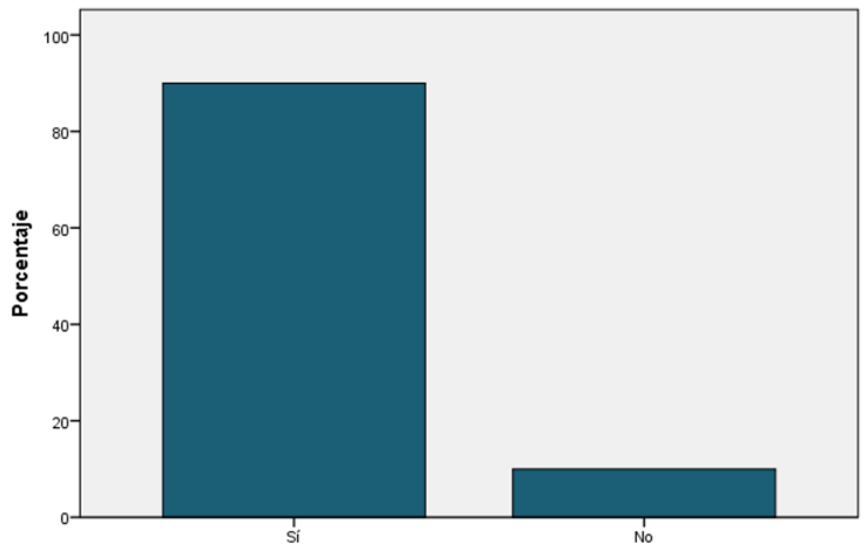

Figura 6: Eufemismos y disfemismos en el Aula de Enlace
¿Te han llamado alguna vez "españolito/a", "blanquito/a" o "europeíto/a"?

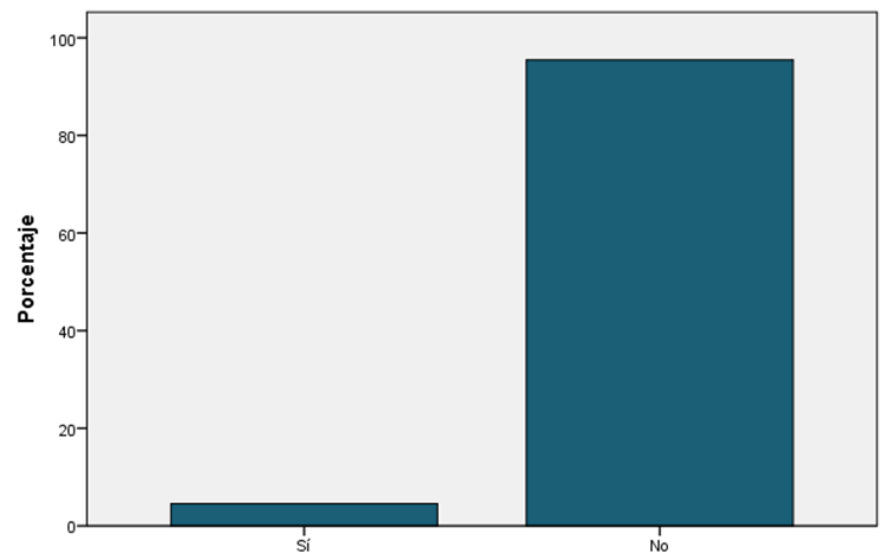

Figura 7: Eufemismos y disfemismos en el aula ordinaria

A pesar de que un $95,5 \%$ de los alumnos españoles no ha recibido eufemismos de este estilo, el 100\% ha escuchado decírselos a personas inmigrantes. La percepción de estos fenómenos lingüísticos también es notablemente diferente entre ambos grupos. Mientras un $40,9 \%$ de los alumnos del aula ordinaria se posiciona, dentro de una escala de Likert de cinco niveles, en la neutralidad, un 50\% de los alumnos del Aula de Enlace asegura que les parecen muy mal. También se han recogido datos de la intención percibida sobre aquellas personas que emplean este tipo de eufemismos y disfemismos racistas y xenófobos, mostrando que un $36,4 \%$ de los alumnos españoles cree que no tienen ninguna intención, a diferencia del $80 \%$ de los alumnos extranjeros que cree que la intención es mala. Ningún sujeto ha considerado que la intención sea buena.

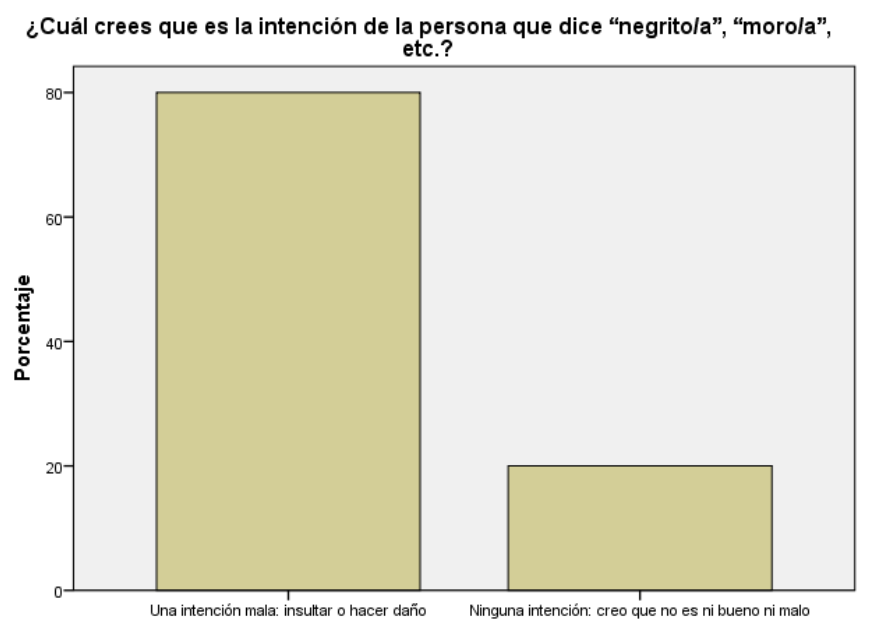

Figura 7. Percepción eufemismos y disfemismos Aula de Enlace

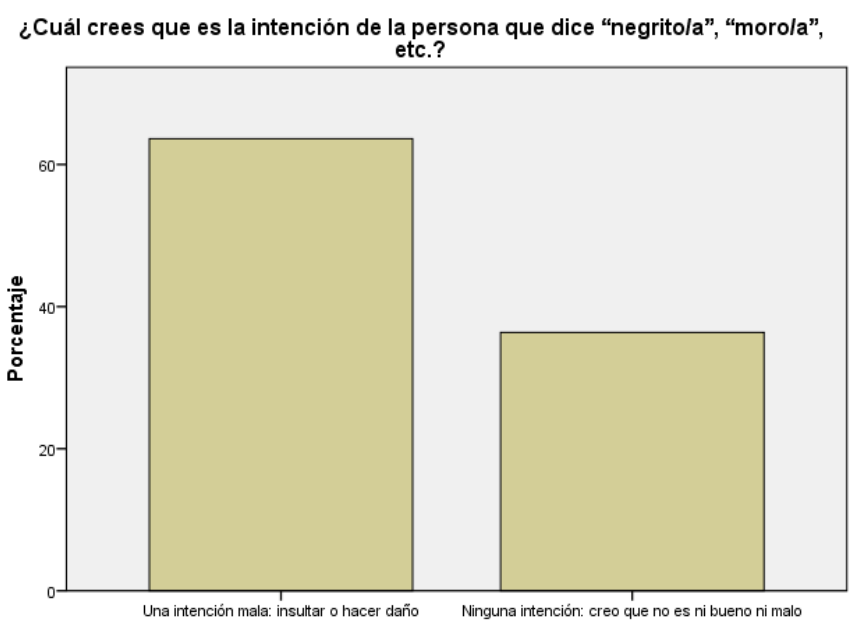

Figura 8. Percepción eufemismos y disfemismos aula ordinaria

En consideración a las frases hechas como «no hay moros en la costa» o «trabajar como un negro», el 100\% de la muestra reconoce haberlas escuchado en alguna ocasión. 
En el Aula de Enlace, al 40\% le hacen sentir muy mal, al 50\% mal y al $10 \%$ indiferente. En el aula ordinaria, al 45,5\% le hacen sentir muy mal, al 31,8\% mal, al 13,6\% indiferente y al 9,1 bien.

Respecto a las bromas y chistes racistas, el 50\% del grupo Aula de Enlace afirma haberse sentido ofendidos a veces en oposición al 95,5\% del grupo aula ordinaria que no ha recibido bromas y chistes racistas. Después, se les pregunta si alguna vez han hecho ellos una broma que haya incomodado a alguien, obteniendo un 45,5\% de síes entre los alumnos españoles y un 30\% entre los alumnos extranjeros. Ante ello, el 100\% de los alumnos extranjeros pidió disculpas mientras que el 70\% de los alumnos españoles cree que fueron malinterpretados.

\subsection{Grupo de análisis 4. Comunicación no verbal}

Abrimos este último grupo de análisis poniendo sobre la mesa la cuestión de la presuposición de inferioridad intelectual de las personas extranjeras. El 63,6\% de los estudiantes españoles reconoce haber hablado o haber escuchado a otra persona hablar a una persona de otra raza como si no entendiera nada. Parece que esta es una realidad a la que se enfrentan nuestros estudiantes de ELE, pues el 70\% siente que siempre o casi siempre les hablan desde una posición de superioridad intelectual.

Tabla 7. Presunción de inferioridad intelectual

¿Alguna vez has sentido que, por ser de otro país, te hablan como si no entendieras nada?

\begin{tabular}{|c|c|c|c|c|c|}
\hline & & Frecuencia & Porcentaje & Porcentaje válido & Porcentaje acumulado \\
\hline \multirow[t]{5}{*}{ Válido } & Siempre & 3 & 30,0 & 30,0 & 30,0 \\
\hline & Casi siempre & 4 & 40,0 & 40,0 & 70,0 \\
\hline & A veces & 2 & 20,0 & 20,0 & 90,0 \\
\hline & Casi nunca & 1 & 10,0 & 10,0 & 100,0 \\
\hline & Total & 10 & 100,0 & 100,0 & \\
\hline
\end{tabular}

«Una mujer extranjera se acerca a unos turistas a venderles algo. Un chico del grupo la mira con desconfianza y no le habla. Otra chica agarra fuerte su bolso». Ante esta situación, el $22,7 \%$ de los estudiantes españoles no cree que la mujer pueda sentirse atacada a pesar de que no le hayan dicho nada. El 100\% de los alumnos del Aula de Enlace coincide en que sí. También, el $100 \%$ de ellos cree que el comportamiento del grupo es racista, acompañados por apenas la mitad del otro grupo, en el que el 45,5\% no percibe un comportamiento racista en este supuesto. El 80\% de los aprendientes de español opina que el grupo no se comportaría igual si la mujer fuera española.

Haciendo alusión a la proxémica, el $80 \%$ de los estudiantes extranjeros siente que alguna vez se han alejado de ellos, dejando una mayor distancia física, por ser de otro país. El 100\% de los alumnos españoles nunca se ha visto en esta situación. 
Tabla 8. Proxémica en el Aula de Enlace

¿Alguna vez has sentido que la gente se ha alejado de ti por ser de otro país?

\begin{tabular}{|c|c|c|c|c|c|}
\hline & & Frecuencia & Porcentaje & Porcentaje válido & Porcentaje acumulado \\
\hline \multirow[t]{3}{*}{ Válido } & Sí & 8 & 25,0 & 80,0 & 80,0 \\
\hline & No & 2 & 6,3 & 20,0 & 100,0 \\
\hline & Total & 10 & 31,3 & 100,0 & \\
\hline Perdidos & Sistema & 22 & 68,8 & & \\
\hline Total & & 32 & 100,0 & & \\
\hline
\end{tabular}

Tabla 9. Proxémica en el aula ordinaria

¿Alguna vez has sentido que la gente de otro país se alejaba de ti por ser español/a?

\begin{tabular}{|c|c|c|c|c|c|}
\hline & & Frecuencia & Porcentaje & Porcentaje válido & Porcentaje acumulado \\
\hline Válido & No & 22 & 68,8 & 100,0 & 100,0 \\
\hline Perdidos & Sistema & 10 & 31,3 & & \\
\hline Total & & 32 & 100,0 & & \\
\hline
\end{tabular}

Para acabar, se proyectó una escena en la que una mujer francesa les presenta a su novio marfileño a sus padres, interesante desde el punto de vista de la comunicación no verbal. En la primera tabla podemos observar lo que opinan los alumnos españoles respecto a lo que opinan los alumnos extranjeros, recogido en la última tabla.

Tabla 10. Escena en el aula ordinaria

¿Cómo describirías esta escena?

\begin{tabular}{llrrrr}
\hline & Frecuencia & Porcentaje & Porcentaje válido & Porcentaje acumulado \\
\hline Válido & Graciosa & 10 & 45,5 & 45,5 & 45,5 \\
& Incómoda & 11 & 50,0 & 50,0 & 95,5 \\
& Agradable & 1 & 4,5 & 4,5 & 100,0 \\
& Total & 22 & 100,0 & 100,0 & \\
& & & & &
\end{tabular}

Tabla 11. Escena en el Aula de Enlace

¿Cómo describirías esta escena?

\begin{tabular}{|c|c|c|c|c|c|}
\hline & & Frecuencia & Porcentaje & Porcentaje válido & Porcentaje acumulado \\
\hline Válido & Incómoda & 10 & 100,0 & 100,0 & 100,0 \\
\hline
\end{tabular}




\section{Discusión y conclusiones}

Tal como los datos obtenidos en esta investigación demuestran, podemos confirmar que sí existen diferencias en la percepción de los comportamientos comunicativos racistas entre un grupo de estudiantes inmigrantes de un Aula de Enlace y un grupo de estudiantes españoles. En el análisis de datos se vislumbran perspectivas interesantes que merece la pena discutir.

En primer lugar, respecto a los datos en el país de origen, los pocos alumnos que afirman la existencia de discriminación hacia personas de otros países son procedentes de Marruecos y Argelia. Sin embargo, el porcentaje no es representativo ya que la mayoría de alumnos de los mismos países de origen opinan que no la hay. Es destacable que el 20\% de los sujetos que sí se sentían discriminados en sus países son de género femenino y también procedentes de Marruecos y Argelia. Conforme a la percepción de los propios españoles sobre la discriminación en España que se presenta a continuación, podemos concluir que los sujetos de este estudio tienden a pensar que en sus países no existe la discriminación racial o esta es menor de lo que realmente es.

En segundo lugar y acorde a lo anterior, cabe destacar que los alumnos españoles creen que la discriminación racial en España es menor en comparación con lo que creen los alumnos extranjeros. Esto se ve reforzado en el porcentaje que asevera tener compañeros racistas, siendo menor en los alumnos nacidos en España que en los estudiantes extranjeros. De este último grupo, los que no consideran tener compañeros racistas son procedentes de Rusia $^{2}$ (10\%) y Marruecos (30\%). Sería interesante ahondar en cómo se relacionan los jóvenes marroquíes, porque el hecho de que la mayoría de veces formen pandillas entre ellos puede influir en un falso sentimiento de integración.

Retomando el análisis del Aula de Enlace, los resultados ponen en duda la eficacia de esta medida para la integración sociocultural (sin entrar en lo lingüístico) de los alumnos recién llegados, tal y como se esbozaba en el marco teórico. A pesar de que los cuestionarios se pasaron en el tercer trimestre del curso, el $80 \%$ de los alumnos se siente discriminado y el $70 \%$ de ellos lo atribuye a ser de otro país, por lo que se concluye que las Aulas de Enlace no son una medida eficaz para la integración sociolingüística de los alumnos extranjeros. Esto, además, refleja una realidad social que tiene completamente integrados los insultos racistas (96,9\%). Las razones de ello ya han sido abordadas en la revisión literaria, pero podríamos reiterar el menosprecio de

\footnotetext{
${ }^{2}$ Existe un outlander dentro del grupo Aula de Enlace que, en muchas de las cuestiones, difiere estadísticamente de la mayoría de sus compañeros. Por ejemplo, es el único que opina que casi nunca hay discriminación en España hacia las personas de otros países, forma parte del 20\% que no se siente discriminado en el colegio, es el único que no ha recibido eufemismos racistas, el único que se posiciona neutral ante la fraseología xenófoba, el único que nunca ha recibido bromas o chistes racistas y el único al que casi nunca le han tratado con presuposición de inferioridad intelectual. ¿A qué podría deberse si no fuera porque este alumno tiene la piel blanca? Posiblemente, la explicación sea tan simple como que es el único sujeto dentro de este grupo que es del Norte Global. Esto nos hace volver a Van Dijk (2003a), que asegura que el imaginario colectivo racista conecta de una manera mucho más directa si se trata de los países del Sur.
} 
lo ajeno y el temor a lo desconocido (Calero, Forgas y Lledó, 2002) o la perspectiva histórica y sus lastres en los medios de comunicación, los discursos políticos, los sistemas educativos y laborales y el lenguaje cotidiano de su comunidad (Van Dijk, 2010).

A nivel lingüístico, resulta inquietante advertir que solo el 40,6\% de los sujetos considera la comunicación no verbal como un posible comportamiento discriminatorio. Este análisis evidencia el claro peso que se le otorga a la comunicación verbal frente a la comunicación no verbal y el papel crucial que juega en la comunicación. Este dato se contrastará más adelante con la percepción contextualizada de una situación no verbal potencialmente discriminatoria, en la que los alumnos entienden mayoritariamente la conducta racista. Esta aparente contradicción revela que es más fácil advertir un comportamiento no verbal cuando se muestra un ejemplo concreto (Ortuño, 2016).

Respecto a los disfemismos y eufemismos racistas y xenófobos, el 100\% de los alumnos españoles afirma estar familiarizado con ellos a pesar de que el 63,6\% declara que la intención de quien los usa es mala (insultar o hacer daño). Es en este punto donde nace la reflexión sobre la necesidad de adaptar nuestro lenguaje a nuestro pensamiento y viceversa, como señalaba Islas (2005). De lo contrario, una mayoría seguirá convencida de que está mal llamar «negrita» a una persona, pero optará por no pedir disculpas ante una broma o comentario que haya podido ofenderla (70\%). Otra de las conclusiones que nos deja este análisis es que la creencia de ser malinterpretado es mayor en los sujetos españoles que en los sujetos extranjeros. Esto guarda una relación directa con los infortunios que, como explica Salgueiro (2008), ocurren cuando hay un desacierto en un acto de habla. Este autor asegura que hay mucho de cultural en la manera en que reaccionamos ante los infortunios, como es el caso de pedir disculpas o exculparse en las interpretaciones de los demás.

Otro de los asuntos que los alumnos del Aula de Enlace aportan para la revaloración de nuestra lengua en el ámbito de la diferencia étnica y cultural es la presuposición de inferioridad intelectual. El $90 \%$ de ellos asegura haber sentido que, no por ser aprendientes del idioma sino por ser inmigrantes, la comunidad de habla en la que se desenvuelven les trata con cierta condescendencia moral. Por no hablar de la proxémica como una forma más de tachar a estos individuos, de perpetuar los tópicos racistas y de negar su integración plena en una sociedad que presume ser multicultural. El 80\% de los alumnos extranjeros ha sentido alguna vez que se alejaban de ellos por la calle y lo asocian a ser de otro país. Esto revela el hecho de que los alumnos extranjeros, pese a tener un nivel lingüístico de español no muy alto, detectan e interpretan la conducta no verbal.

Siguiendo con la percepción de los comportamientos racistas no verbales, presentados en los cuestionarios mediante el supuesto práctico de la mujer extranjera que se acerca a un grupo de españoles y estos reaccionan ignorándola y apartando sus pertenencias, parece que la discusión no se encuentra en la dificultad de reconocer el comportamiento racista no verbal sino en la procedencia de los sujetos. El 100\% de los alumnos extranjeros frente al 77,3\% de los alumnos españoles coincide en que esta mujer pueda sentirse atacada pese a la ausencia de lenguaje verbal. Juzgando si el 
comportamiento del grupo es racista, aparece una disonancia respecto al género de la muestra: proporcionalmente, un mayor número de chicas percibe el comportamiento racista de esta situación. Esto podría ser un indicio de que las mujeres atienden más a las señales no verbales que los hombres, algo que autores como Fernández y Valero (2004) ya han desgranado atendiendo a las diferencias de género en el sistema cultural, kinestésico, paralingüístico y proxémico-cronémico.

Por último, la escena cinematográfica es clasificada por la totalidad de los alumnos del Aula de Enlace como incómoda, mientras un 45,5\% de los alumnos del aula ordinaria la clasifican como graciosa. Estos datos revelan la facilidad con la que el racismo se perpetúa en el imaginario colectivo a través del cine y otras muchas vías que trascienden en nuestro pensamiento, en nuestro lenguaje y en nuestros actos (Van Dijk, 2010).

El ser que piensa no es distinto del ser que comunica y del ser que hace. Mediante esta investigación se han pretendido enlazar estas perspectivas como eje vertebral de una muestra de comunidad de habla concreta, formada por miles de personas que cada día tienen la libertad de escoger una palabra u otra, con todas las consecuencias que ello puede suponer. Como se ha visto con los resultados del Aula de Enlace, las palabras y los gestos pesan, sobre todo para quienes se convierten en una barrera.

Las conductas comunicativas racistas forman parte de nuestra realidad social y de nuestro lenguaje verbal y no verbal. Por eso, para los alumnos españoles, muchas de estas conductas pasan inadvertidas y son aparentemente inofensivas e incluso graciosas. La relevancia de esta investigación reside en los puntos comunes y no comunes en la percepción y la interpretación de dos grupos de sujetos cuya mayor diferencia categórica es haber nacido en puntos distintos y tener diferentes lenguas maternas.

Exponer la capacidad del lenguaje para reproducir un comportamiento racista y discriminatorio puede hacernos recapacitar sobre nuestro uso del mismo y dar lugar a unas conductas comunicativas más críticas y responsables. Esta es la clave donde radica el sentido y la importancia del artículo. Como profesores de ELE, no podemos perder de vista que, cada día en nuestras clases, tenemos la oportunidad y la responsabilidad de enseñar el uso de una lengua, con todas sus construcciones, implicaciones y horizontes.

Nosotros estamos acostumbrados a desarrollarnos en ambientes socioeducativos con personas de distintas procedencias que merecen el mismo respeto que cualquier otra. A la vista de los resultados queda que no siempre reciben el trato comunicativo que desearían. Está en manos de todos, en especial de aquellos que ya hemos tomado una cierta conciencia, cambiar este tipo de conductas. Medidas como las Aulas de Enlace pueden ser, como lo son en su planteamiento, unas oportunidades excelentes para «integrar» a quienes todavía tienen que esforzarse por hacerlo. Sin embargo, estas medidas deben ser evaluadas, ajustadas y reinventadas cuantas veces se precise para que sean efectivas y puedan cumplir sus objetivos en la realidad de los alumnos. 


\section{Agradecimientos}

A Ignacio Ceballos Viro, de quien tanto he aprendido y cuya guía ha sido inestimable para esta publicación, y a mi compañero de profesión Juan José Santa Engracia de Pedro.

\section{Referencias bibliográficas}

BAÑóN, A. M. (2002). Discurso e inmigración: propuestas para el análisis de un debate social. Editum. Recuperado de: https://books.google.es/books?hl=es\&lr=\&id=08HUwOteiEcC\&oi=fnd\&pg=PA7\& $\mathrm{dq}=\mathrm{an} \% \mathrm{C} 3 \%$ A1lisis + semi $\% \mathrm{C} 3 \%$ B3tico+discurso+racista\&ots=HgEwL8QKB1\&sig $=$ aeidw4P8VWIzOmoLXIw83--7iVM\#v=onepage $\& \mathrm{q}=$ interpret $\& \mathrm{f}=$ false

BYRAM, M. Y FLEMING, M. (2001). Perspectivas interculturales en el aprendizaje de idiomas. Enfoques a través del teatro y la etnografía. Cambridge University Press, Madrid.

CALERO, M. Á., FORGAS, E., \& LLEDÓ, E. (2002). La presencia del racismo en el discurso lexicográfico: su repercusión en la enseñanza. Textos: didáctica de la lengua y de la literatura, 2002 núm. 31, p. 65-74. Recuperado de: https://repositori.udl.cat/bitstream/handle/10459.1/59878/006647.pdf?seque nce $=1$ \&isAllowed $=\mathrm{y}$

CARRERAS I GOICOECHEA, M., PÉREZ VÁZQUEZ, E. (2010). La mediación lingüística y cultural y su didáctica. Bolonia: Bononia University Press. Recuperado de: https://arpi.unipi.it/handle/11568/1074116

CHOMSKY, N. (2001). La (des) educación. Barcelona, España: Crítica.

CRESPO-FERNÁNDEZ, E. (2005). El eufemismo, el disfemismo y los procesos mixtos: la manipulación del referente en el lenguaje literario inglés desde mediados del siglo XIX hasta la actualidad (Doctoral dissertation, Universitat d'Alacant-Universidad de Alicante).

CONSEJO, D. E. (2001). Marco común de referencia para las lenguas: aprendizaje, enseñanza y evaluación (MCER).

DASSETTO, F. (2004). Más allá de lo intercultural: los retos de la co-inclusión: Lo intercultural: entusiasmo, lítote y eufemismo. Revista CIDOB d'afers internacionals, 99-111. Recuperado de: https://www.jstor.org/stable/40586097?seq=1

DÍAZ PÉREZ, J. C. (2012). Pragmalingüística del disfemismo y la descortesía: Los actos de habla hostiles en los medios de comunicación virtual. Recuperado de: https://earchivo.uc3m.es/bitstream/handle/10016/15682/Tesis_Doctoral_Juan_Carlos_Di az_Perez_UC3M_2012.pdf

DOMÍNGUEZ, P. J. C., (2004). La función social y cognitiva del eufemismo y del disfemismo. Panacea, 5(15), 45-51. Recuperado de: https://www.tremedica.org/wp-content/uploads/n15_tribunaChamizoDominguez.pdf 
FERNÁNDEZ, E. E., \& VALERO, A. L. (2004). Diferencias de género y comunicación: aspectos no verbales y propuestas didácticas. Didáctica. Lengua y Literatura, 16, 45-56.

FREIRE, P. (2003). Pedagogía del oprimido. Barcelona, España: Siglo XXI.

GARCÍA, P. (2004). La cultura, ¿universo compartido? La didáctica intercultural en la enseñanza de idiomas. RedELE: Revista electrónica de Didáctica ELE, 1-6. Recuperado de: https://www.educacionyfp.gob.es/dam/jcr:bebfb443-e91b4016-a99e-41aec9666b97/2004-redele-0-12garcia-pdf.pdf

GOENECHEA, C., GARCIA-FERNANDEZ, J., \& JIMENEZ, R. A. (2011). Los dilemas de la atención educativa a los alumnos inmigrantes recién llegados. Estudio comparativo de los modelos andaluz (ATAL) y madrileño (Aulas de enlace). Profesorado: Revista de currículum y formación del profesorado, 15:3, 1-16. Recuperado de: https://rodin.uca.es/bitstream/handle/10498/16761/ArticuloProfesorado.pdf?s equence $=1 \&$ isAllowed $=y$

GONZÁLEZ, F. R. (2003). Lenguaje y discriminación racial. En torno a la negritud. Espéculo: Revista de Estudios Literarios, (24), 32. Recuperado de: https://webs.ucm.es/info/especulo/numero24/racismo.html

GONZÁLEZ, M. P., CORNEJO, J. M., \& ROCA-CORTÉS, N. (1999). Identidades culturales y lingüísticas: elaboración y afinamiento de tipologías. Revista de Psicología Social, 14(1), 107-126. Recuperado de: https://www.tandfonline.com/doi/abs/10.1174/021347499760260109

Instrucciones del 16 de julio de 2003 de la Viceconsejería de Educación de la Comunidad de Madrid por las que se regulan, con carácter experimental, las Aulas de Enlace del programa "Escuelas de Bienvenida" para la incorporación de alumnado extranjero al sistema educativo. Recuperado de: http://www.madrid.org/bvirtual/BVCM001671.pdf

ISLAS ASAÏS, H. (2005). Lenguaje y discriminación. México: CONAPRED. Recuperado de: http://repositorio.dpe.gob.ec/bitstream/39000/944/1/CONAPRED-032.pdf

LENTIN, A. (2016). Racism in public or public racism: Doing anti-racism in 'postracial'times. Ethnic and Racial Studies, 39(1), 33-48. Recuperado de: https://www.tandfonline.com/doi/abs/10.1080/01419870.2016.1096409

LEPE-CARRIÓN, P. (2018). Educación, racismo cultural y seguridad nacional: la escuela intercultural en contextos de violencia. Educação e Pesquisa, 44. Recuperado de: https://www.scielo.br/scielo.php?pid=S1517-

97022018000100445\&script=sci_arttext

MAGRO, J. (2016). Lengua y racismo-motivación, competencia y conciencia lingüística en la clase de español como segunda lengua: Integración de contenidos relacionados con la dimensión socio-política del lenguaje en un acercamiento content-based. City University of New York (CUNY). CUNY Academic Works. Recuperado de: https://academicworks.cuny.edu/cgi/viewcontent.cgi?article $=2539 \&$ context $=$ gc etds 
MÁRMOL, G. A. (2019). Actitudes frente a la mediación lingüística en un contexto de educación secundaria. Revista Nebrija de Lingüística Aplicada a la Enseñanza de Lenguas, 13(27), 112-128. Recuperado de: https://34.252.45.248/revistalinguistica/article/view/322

MATIAS, C. E., \& DIANGELO, R. (2013). Beyond the Face of Race: Emo-Cognitive Explorations of White Neurosis and Racial Cray-Cray. Educational Foundations, 27, 3-20. Recuperado de: https://files.eric.ed.gov/fulltext/EJ1065640.pdf

MILÁNS, P. (2007). Las aulas de enlace: un islote de bienvenida. En L. Martín Rojo, y L. Mijares (eds.), Voces del aula. Etnografías de la escuela multilingüe. Madrid: CIDE.

MOLINA-NIÑIROLA, P. A. (2005). “iJau, rostro pálido!": análisis sociolingüístico del discurso etno-racial en el Western. Tonos digital: Revista de estudios filológicos, (10), $27 . \quad$ Recuperado de: https://www.um.es/tonosdigital/znum10/secciones/corpjau.htm\#: :text=El\%20racismo\%20tiene\%20desde\%20luego,de\%20las\%20raza s\%20\%E2\%80\%9Cinferiores\%E2\%80\%9D

ORTUÑO, E. (2016). Lenguaje y racismo. Revista de la Academia Nacional de Letras, (12), 77-83.

PIZARRO, A. (ed.) (2018): Linguistic Taboo Revisited. Novel Insights from Cognitive Perspectives, Berlín, Mouton de Gruyter.

PLACENCIA, M. E. (2008). 'Hola María': racismo y discriminación en la interacción interétnica cotidiana en Quito. Discurso \& Sociedad, 2(3), 573-608. Recuperado de: http://www.dissoc.org/ediciones/v02n03/DS2(3)Placencia.pdf

POYATOS, F. (2003). La comunicación no verbal: algunas de sus perspectivas de estudio e investigación. Revista de investigación lingüística, 6(2), 68-83. Recuperado de: https://digitum.um.es/digitum/bitstream/10201/17741/1/5591.pdf

RAFKY, DAVID M., (1970). The semantics of negritude. American Speech, 45, 1-2, 30-43. Recuperado de: https://www.jstor.org/stable/455060?seq=1

SALGUEIRO, A. (2008). Cómo hacer cosas malas con palabras: actos ilocucionarios hostiles y los fundamentos de la teoría de los actos de habla. Crítica (México, DF), 40(118), 3-27. Recuperado de: http://www.scielo.org.mx/pdf/rhfi/v40n118/0011-1503-rhfi-40-118-3.pdf

SEMPERE, R. S. (1971). El eufemismo como fenómeno lingüístico. Boletín de la Real Academia Española, 51(192), 175-190. Recuperado de: https://apps.rae.es/BRAE_DB_PDF/TOMO_LI/CXCII/Senabre_175_189.pdf

TROVATO, G. (2014). Las estrategias de la mediación lingüística para fomentar el aprendizaje de las destrezas orales bilingües (español-italiano). Dialogía, 8(1), 162180.

Recuperado

de: http://www.contrastiva.it/baul_contrastivo/dati/barbero/Trovato\%20destrezas \%20orales\%202014.pdf

VAN DIJK, T. (2001). Discurso y racismo. Persona y sociedad, 16(3), 191-205. Recuperado de: http://www.discursos.org/Art/Discurso\%20y\%20racismo.pdf

VAN DIJK, T. (2003a). Dominación étnica y racismo discursivo en España y América Latina: América Latina (Vol. 891010). Editorial Gedisa. 
VAN DIJK, T. (2003b). La multidisciplinariedad del análisis crítico del discurso: un alegato a favor de la diversidad. Métodos de análisis crítico del discurso, 143-177. Recuperado de: http://www.discursos.org/Art/La\%20multidisciplinariedad.pdf VAN DIJK, T. (2010). Análisis del discurso del racismo. Crítica y emancipación, 3, 65-94. Recuperado de: http://biblioteca.clacso.edu.ar/clacso/se/20120301125018/CyE3.pdf\#page=66

\section{Apéndice}

\begin{tabular}{|c|c|c|}
\hline Dimensión & Indicador & Preguntas \\
\hline $\begin{array}{l}\text { Datos } \\
\text { personales }\end{array}$ & $\begin{array}{l}\text { Procedencia } \\
\text { Edad } \\
\text { Sexo }\end{array}$ & $\begin{array}{l}\text { 1. ¿De dónde eres? } \\
\text { 2. ¿Cuántos años tienes? } \\
\text { 3. ¿Eres chico o chica? }\end{array}$ \\
\hline $\begin{array}{l}\text { Datos de } \\
\text { estudio en } \\
\text { origen }\end{array}$ & $\begin{array}{l}\text { Racismo y } \\
\text { discriminación en } \\
\text { sus países de } \\
\text { origen } \\
\text { Sentimiento de } \\
\text { discriminación } \\
\text { Razones de la } \\
\text { discriminación }\end{array}$ & $\begin{array}{l}\text { 4. ¿En el país donde naciste hay discriminación hacia las personas de } \\
\text { otros países? } \\
\text { Sí } \square \text { No } \square \\
\text { 5. ¿Te sentías discriminado/a alli? } \\
\text { Sí } \square \text { No } \square \\
\text { 6. ¿Por qué te sentías discriminado/a? } \\
\text { Por mi manera de ser } \square \\
\text { Por mis gustos o aficiones } \square \\
\text { Por otras razones } \square \text { : } \\
\text { No me sentía discriminado/a } \square\end{array}$ \\
\hline $\begin{array}{l}\text { Datos de } \\
\text { estudio locales }\end{array}$ & $\begin{array}{l}\text { Racismo y } \\
\text { discriminación en } \\
\text { España } \\
\text { Sentimiento de } \\
\text { discriminación } \\
\text { Razones de la } \\
\text { discriminación } \\
\text { Racismo y } \\
\text { discriminación en } \\
\text { el colegio } \\
\text { Percepción de los } \\
\text { ataques racistas }\end{array}$ & $\begin{array}{l}\text { 7. ¿En España hay discriminación hacia las personas de otros países? } \\
\text { Siempre } \square \text { Casi siempre } \square \text { A veces } \square \text { Casi nunca } \square \text { Nunca } \square \\
\text { 8. ¿Te sientes discriminado/a en el colegio? } \\
\text { Sí } \square \text { No } \square \\
\text { 9. Si te sientes discriminado/a, ¿por qué te sientes discriminado/a? } \\
\text { Por mi manera de ser } \square \\
\text { Por mis gustos o aficiones } \square \\
\text { Por ser de otro país } \square \\
\text { Por otras razones } \square \text { : } \\
\text { 10. ¿Tienes compañeros/as racistas? } \\
\text { Sí } \square \text { No } \square \\
\text { 11.Si has percibido alguna vez ataques racistas, ¿de qué tipo eran? } \\
\text { Marca todas las opciones que consideres. } \\
\text { Insultos } \square \text { Marginación } \square \\
\text { Amenazas } \square \text { Gestos } \square \text { Otros } \square \text { : }\end{array}$ \\
\hline Lingüística & $\begin{array}{l}\text { Eufemismos, } \\
\text { disfemismos y } \\
\text { apelativos } \\
\text { despectivos }\end{array}$ & $\begin{array}{l}\text { 12. ¿Te han llamado alguna vez "negro /a", "chinito/a", "moro/a", } \\
\text { "morenito/a", "persona de color", "sudaca", "terrorista" o } \\
\text { "inmigrante"? } \\
\text { Sí } \square \text { No } \square \\
\text { 13. ¿Cómo te parece que te lo llamen? } \\
\text { ¿Cómo preferírías que se refirieran a ti? }\end{array}$ \\
\hline
\end{tabular}




\begin{tabular}{|c|c|c|}
\hline & $\begin{array}{l}\text { Intención } \\
\text { percibida de estos } \\
\text { disfemismos y } \\
\text { apelativos } \\
\text { despectivos } \\
\text { Fraseología } \\
\text { Intención } \\
\text { percibida de estas } \\
\text { frases hechas }\end{array}$ & $\begin{array}{l}\text { 14. ¿Cuál crees que es la intención de la persona que dice "negrito/a", } \\
\text { "moro/a", etc.? } \\
\text { Una intención mala: insultar o hacer daño } \square \\
\text { Ninguna intención: creo que no es ni bueno ni malo } \square \\
\text { Una intención buena: caer bien o hacer amigos } \square \\
\text { 15. ¿Has escuchado alguna vez estas frases? } \\
\text { https://www.youtube.com/watch?v=GPj6ydiDAVI } \\
\text { Sí } \square \text { No } \square \\
\text { ¿Cómo te hacen sentir? } \\
\text { Muy mal / Mal/ Me da igual / Bien / Muy bien } \\
\text { no entendieras nada? } \\
\text { https://www.youtube.com/watch?v=Gi9wRszZQU0 } \\
\text { Siempre } \square \text { Casi siempre } \square \text { A veces } \square \text { Casi nunca } \square \text { Nunca } \square \\
\text { 17. ¿Alguna vez te han hecho una broma o chiste racista con el que te } \\
\text { hayas sentido ofendido/a? } \\
\text { Siempre } \square \text { Casi siempre } \square \text { A veces } \square \text { Casi nunca } \square \text { Nunca } \square \\
\text { 17a. ¿Crees que alguna vez has hecho tú una broma que haya } \\
\text { incomodado a alguien? } \\
\text { Sí } \square \text { No } \square \\
\text { 17b. Si en la anterior has marcado que sí, ¿pediste disculpas a esa } \\
\text { persona o crees que te malinterpretó? } \\
\text { Pedí disculpas } \square \text { Creo que me malinterpretó } \square\end{array}$ \\
\hline $\begin{array}{l}\text { Comunicación } \\
\text { no verbal }\end{array}$ & $\begin{array}{l}\text { Proxémica } \\
\text { Cinésica: } \\
\text { Expresión facial y } \\
\text { corporal }\end{array}$ & $\begin{array}{l}\text { 18. "Una mujer extranjera se acerca a unos turistas a venderles algo. } \\
\text { Un chico del grupo la mira con desconfianza y no le habla. Otra chica } \\
\text { agarra fuerte su bolso". ¿Crees que la mujer puede sentirse atacada, a } \\
\text { pesar de que no le hayan dicho nada? } \\
\text { Sí } \square \text { No } \square \\
\text { 18a. ¿Crees que el comportamiento del grupo es racista? } \\
\text { Sí } \square \text { No } \square \\
\text { 18b. ¿Crees que actuarían igual si la mujer fuera española? } \\
\text { Sí } \square \text { No } \square \\
\text { 19. ¿Alguna vez has sentido que la gente se ha alejado de ti por ser de } \\
\text { otro país? https://www.youtube.com/watch?v=Y6 uXO0kgAc } \\
\text { Sí } \square \text { No } \square \\
\text { 20. ¿Cómo describirías esta escena? } \\
\text { https://www.youtube.com/watch?v=LjEEtnl4RRg } \\
\text { Graciosa } \square \text { Incómoda } \square \text { Agradable } \square\end{array}$ \\
\hline
\end{tabular}


AULA ORDINARIA

\begin{tabular}{|c|c|c|}
\hline Dimensión & Indicador & Preguntas \\
\hline Datos personales & $\begin{array}{l}\text { Procedencia } \\
\text { Edad } \\
\text { Sexo }\end{array}$ & $\begin{array}{l}\text { 1. ¿De dónde eres? } \\
\text { 2. ¿Cuántos años tienes? } \\
\text { 3. ¿Eres chico o chica? }\end{array}$ \\
\hline Datos de estudio locales & $\begin{array}{l}\text { Racismo y } \\
\text { discriminación en } \\
\text { España } \\
\text { Sentimiento de } \\
\text { discriminación } \\
\text { Razones de la } \\
\text { discriminación } \\
\\
\text { Racismoy } \\
\text { discriminación en } \\
\text { el colegio } \\
\text { Percepción de los } \\
\text { ataques racistas }\end{array}$ & $\begin{array}{l}\text { 4. ¿En España hay discriminación hacia las personas de } \\
\text { otros países? } \\
\text { Siempre } \square \text { Casi siempre } \square \text { A veces } \square \text { Casi nunca } \square \text { Nunca } \\
\square \\
\text { 5. ¿Te sientes discriminado/a en el colegio? } \\
\text { Si } \square \text { No } \square \\
\text { 6. ¿Por qué te sientes discriminado/a? } \\
\text { Por mi manera de ser } \square \\
\text { Por mis gustos o aficiones } \square \\
\text { Por otras razones } \square \text { : } \\
\text { No me siento discriminado/a } \square \\
\text { 7. ¿Tienes compañeros/as racistas? } \\
\text { Sí } \square \text { No } \square \\
\text { 8. ¿En qué crees que consiste un ataque racista? Marca } \\
\text { todas las opciones que consideres. } \\
\text { Insultos } \square \text { Marginación } \square \\
\text { Amenazas } \square \text { Gestos } \square \text { Otros } \square \text { : }\end{array}$ \\
\hline \multirow[t]{2}{*}{ Lingüística } & $\begin{array}{l}\text { Intención } \\
\text { percibida de estos } \\
\text { eufemismos y } \\
\text { apelativos } \\
\text { despectivos } \\
\text { Fraseología } \\
\text { Intención } \\
\text { percibida de estas } \\
\text { frases hechas }\end{array}$ & 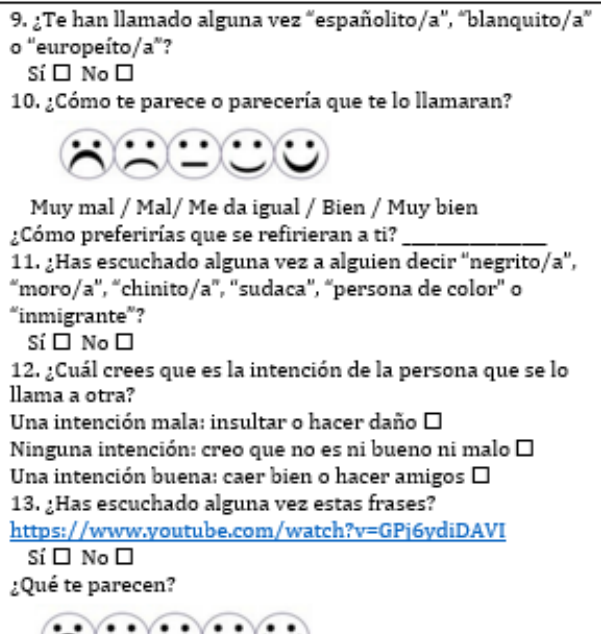 \\
\hline & 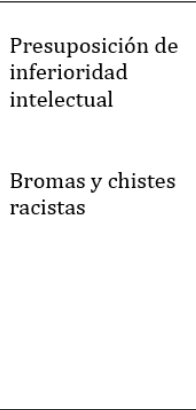 & $\begin{array}{l}\text { 14. ¿Alguna vez has hablado o escuchado a otra persona } \\
\text { hablar a una persona de otra raza como si no entendiera } \\
\text { nada? } \\
\text { https://www.youtube.com/watch?v=Gi9wRszZQU0 } \\
\text { Sí } \square \text { No } \square \\
\text { 15. ¿Alguna vez te han hecho una broma o chiste racista con } \\
\text { el que te hayas sentido ofendido/a? } \\
\text { Sí } \square \text { No } \square \\
\text { 16. ¿Crees que alguna vez has hecho tú una broma que haya } \\
\text { incomodado a alguien? } \\
\text { Sí } \square \text { No } \square \\
\text { 17. Si en la anterior has marcado que sí, ¿pediste disculpas a } \\
\text { esa persona o crees que te malinterpretó porque tú no lo } \\
\text { hacías con mala intención? } \\
\text { Pedí disculpas } \square \text { Creo que me malinterpretó } \\
\end{array}$ \\
\hline Comunicación no verbal & $\begin{array}{l}\text { Desconfianza } \\
\text { Ausencia de } \\
\text { contacto visual y } \\
\text { verbal }\end{array}$ & $\begin{array}{l}\text { 18. "Una mujer extranjera se acerca a unos turistas a } \\
\text { venderles algo. Un chico del grupo la mira con desconfianza } \\
\text { y no le habla. Otra chica agarra fuerte su bolso". ¿Crees que } \\
\text { la mujer puede sentirse atacada, a pesar de que no le hayan } \\
\text { dicho nada? } \\
\text { Sí } \square \text { No } \square \\
\text { ¿Crees que el comportamiento del grupo es racista? } \\
\text { Sí } \square \text { No } \square \\
\text { 19. ¿Alguna vez has sentido que la gente de otro país se } \\
\text { alejaba de ti por ser español/a? } \\
\text { https://www.youtube.com/watch?v=Y6 uXO0kgAc } \\
\text { Sí } \square \text { No } \square \\
\text { 20. ¿Cómo describirías esta escena? } \\
\text { https://www.youtube.com/watch?v=LJEEtnl4RRg } \\
\text { Graciosa } \square \text { Incómoda } \square \text { Agradable } \square\end{array}$ \\
\hline
\end{tabular}

